\title{
The Functional Model of Analysis as Middle Ground Meta-Ethics
}

\author{
- Krzysztof Saja -
}

\begin{abstract}
The main purpose of the paper is to present a new framework of meta-ethics which I call the Functional Model of Analysis. It presupposes that the most important meta-ethical question is not "What is the meaning of normative words, sentences and what is the ontological fabric of the moral world?" but "What should morality and ethics be for?". It is a form of meta-ethics that focuses on finding theoretical resources that can be helpful in understanding ongoing ethical debates between disciples of Aristotle, Epicurus, the Stoics, Augustine, Hobbes, utilitarians and Kant, and in building normative ethical theories that can help us to answer normative questions. As an example of such output I will present a formal sketch of Hybrid Function Consequentialism - a normative ethical theory based upon the meta-ethical framework proposed here.
\end{abstract}

Keywords: meta-ethics, normative ethics, methodology, consequentialism

Published online: 15 November 2019

In this paper I will outline a new approach to meta-ethics which I term the Functional Model of Analysis. I believe that it can be fruitful not only as a theoretical, philosophical endeavour, but also as an aid to building a proper normative theory of ethics. I will focus on morality, ethics and meta-ethics, but the project could be expanded into other normative domains such as political philosophy or philosophy of law. However, I will not justify this broader claim here. In the following paragraphs, I will focus on ethics, trying to convince the reader that this new approach should be developed further. By ethics I mean academic, philosophical normative reflection, normative philosophy that tries to shape, criticize or justify any individual and social way of living, public and private norms or institutions from moral point of view.

This paper is divided into four sections, and over the course of it I will narrow my focus to a particular kind of theory that I think may be best suited to obtaining what is needed. In the first section, I briefly review the current status of meta-ethics, present its drawbacks and justify a need to simultaneously start a different kind of research. I outline it in the second section, where I present an account of the Functional Model of Analysis as a version of meta-ethics that is focused on helping to solve problems of normative

Krzysztof Saja

The Department of Ethics

Institute of Philosophy

The University of Szczecin

ul. Krakowska 61/69

71-017 Szczecin 
ethics. In the third section, I discuss three main advantages of this account: it can help to explain the deep content of and reasons for persistent ethical disagreement; it can give reasons for the different structures of moral theories; and it can be used as the foundation of a unifying account of normative ethics. In the fourth section I will deal with some potential problems that might be mentioned as objections to the account proposed here.

\section{High Ground and Middle Ground Meta-Ethics}

Before I begin to fulfil this promise directly, we need to have a look into the condition of modern meta-ethics in analytic philosophy. This can justify the need for the different account that I will try to develop in the next section of the paper.

Somebody who does not know meta-ethics might think - on the basis of the meaning of the term - that it is highly influenced by ethical disputes. This is surprisingly wrong. Although modern meta-ethics began with George E. Moore's $\mathrm{s}^{1}$ belief that in order to solve normative moral problems we first need to find the answer to the meta-ethical question "What is the meaning of such moral terms as good?", in the end that particular question led meta-ethics far away from normative debates. As can be seen in many handbooks of the discipline, meta-ethics is mostly about defining or describing the meaning of moral terms or judgments, analysing the status of corresponding moral properties and facts, analysing important notions like moral knowledge, motivation, reason to act, etc. It is mostly about moral realism, quasi-realism, descriptivism, cognitivism, anti-realism, non-descriptivism, non-cognitivism, emotivism, expressivism and fictionalism. Modern meta-ethics is an abstract philosophical inquiry mainly about philosophy of language, metaphysics with some addition of topics from moral epistemology and moral psychology. ${ }^{2}$ Therefore I will call it high ground meta-ethics (HGM) to contrast it with middle ground meta-ethics (MGM), which I will present later.

A typical pattern of progress in high ground meta-ethics can be described as importing some new philosophical ideas from other fields of philosophy and creatively connecting them with recent meta-ethical debates. This pattern can be seen in widely recognized philosophers such as G.E. Moore, R. Carnap, A. Ayer, Ch. Stevenson, S. Blackburn, A. Gibbard, R. Boyd, J. McDowell, P. Geach, G. Harman, F. Jackson, M. Smith. J.L. Mackie, R. Joyce and many others. This is also a reason why meta-ethics can be, and in fact is, easily broadened into a meta-philosophical or meta-normative discipline. Questions about normativity, at first considered mainly in meta-ethics, are now researched in philosophy of language, epistemology and, even more broadly, as a problem of meta-philosophy. ${ }^{3}$ For example, emotivism, which was a famous doctrine about moral language in the first half of the twentieth century, shifted to the broader claim of expressivism ${ }^{4}$ and even further to global-expressivism. ${ }^{5}$

\footnotetext{
${ }^{1}$ Moore (1903).

${ }^{2}$ To see this, simply browse the table of contents in some handbooks to meta-ethics, e.g. Miller (2003); Fisher (2014); van Roojen (2015).

3 Owens (2002); Karlander (2008); Gibbard (2012); Hazlett (2013); Ridge, and Fletcher (eds.) (2014).

${ }^{4}$ Gibbard (1990); Blackburn (1998); Ridge (2014).

${ }^{5}$ Price et al. (2013).
} 
HGM usually takes for granted that the deep normative concerns which shaped the history of ethics are, at least directly, irrelevant to its field or not really important in meta-ethics inquiries. ${ }^{6}$ Such questions are important only on the level of normative ethics. Therefore meta-ethical questions are not concerned with normative disputes between Aristotle, the Stoics, Christian moral philosophers, Hume, Hobbes, Bentham, Kant or Nietzsche. You can be a successful scholar working in meta-ethics even without knowing the normative ethics and its history. Well-recognized philosophers, who shaped the landscape of the discipline, usually did not do normative or applied ethics at all. The purposes of investigating common meta-ethical problems are usually far different from the reasons for discussing e.g. consequentialism, deontology or virtue ethics and their applications in practice. The progress of HGM was mainly accomplished by introducing new theories of language and meta-physics into the domain of moral philosophy and by discussing different forms of scepticism about the realist and cognitivist nature of ethics. However, the reasons for the progress of HGM were also the reasons for its alienation from the normative domain. If we are sceptical about normative ethics as a cognitive endeavour that tries to find reasonable answers to its questions, why should we treat its research seriously? In the end, most meta-ethical debates were focused on the status of ethics and not on finding tools that can give answers to its questions. From a historical perspective, the Moorean meta-ethics did not set firm foundations for normative ethics, but inflated philosophical theories that are still debated and defended. Such inquiry is as valuable as metaphysics, epistemology, philosophy of language or mind; however, it cannot be seen as an aid to doing normative ethics. Surprisingly, one hundred years of HGM development shows results that are the opposite of the reasonable hopes and dreams which led moral philosophers to pursue HGM in the first decades of the twentieth century. Although meta-ethics cannot address the same questions as first-order ethics, it would be valuable if it fulfilled the hopes that were placed in it at the beginning of its career. This means that its problems and questions should be connected directly with practical ethical issues. Because HGM is far from that purpose, in the following paragraphs I will present an alternative framework of meta-ethics that I believe can be fruitful as a direct aid in pushing normative philosophy further. I will call it the Functional Model of Analysis.

\section{The Functional Model of Analysis as Middle Ground Meta-Ethics}

Meta-ethics could be useful for normative ethics. It can take the form of what I call middle ground meta-ethics (MGM). By this term I mean a philosophical approach rooted in the initial hopes that led to meta-ethical inquiry: it focuses on finding theoretical resources that can be helpful in understanding ongoing ethical debates between disciples of Aristotle, Epicurus, the Stoics, Augustine, Hobbes, the utilitarians and Kant, and in building normative ethical theories that can help us to answer normative questions. MGM is not an alternative to HGM, because they are on different theoretical levels. The two approaches

\footnotetext{
${ }^{6}$ Once more, it can be seen in most contemporary handbooks of meta-ethics that represented well the current dabates in the field, e.g. Miller (2003); Fisher (2014); van Roojen (2015).
} 
can be seen as entirely compatible, potentially even complementary. The only sense in which they might compete is for the attention and interest of philosophers. MGM is a form of meta-ethics that tries to avoid discussion of moral language or metaphysics if such discussion does not bring us closer to proper normative theory. One example of MGM topic can be a discussion about methodology of reflective equilibrium in ethics that was brought to academic attention by John Rawls. ${ }^{7}$ The main purpose of such an inquiry was to justify and explain the methodology that will be used in investigating the normative theory of justice. In this case, the meta-ethical remarks were treated as a preparation for proper, normative investigations. A similar role of HGM can be seen in the work of Richard M. Hare. In his second ${ }^{8}$ and third book ${ }^{9}$ he argued that analysis of the language of morals - the topic that he focused on in his first book - justifies his normative ethical stance, i.e. preference rule utilitarianism.

If any meta-ethical framework can be useful for normative ethics, it needs to fulfil at least two prerequisites: it should be immune from the basic forms of scepticism that drove much research in HGM and should be oriented towards normative ethics and its history. In order to develop fruitful MGM that can help in doing normative ethics, we need at least to assume that normative disputes are about something objective, shared by discussion parties, that can be discovered and recalled as a criterion for successfully ending such debates. If meta-ethics should help us to solve some puzzles of normative-ethics, we do need to have at least a hope that these puzzles are somehow solvable. There is no need to accept a robust ethical realism - a belief that real moral properties or facts exist. We can also adopt a form of cognitivist rationalism which claims that there are some independent reasons that nobody could reasonably reject. If it make sense - and I don't want to argue for or against such claim here - we could accept even some kind of Error Theory and still put some hope in MGM. However, we need to believe that there are some methods to construct or preserve normative discussions and that normative ethics could be helpful in solving at least some moral disagreements. Whatever the theory would be, we need to accept that normative disputes between moral philosophers are somehow reasonably solvable, are about something "objective" that can play the role of reasonable authority for addressing ethical disagreements. Without such assumptions, there is no reason to develop any Middle Ground Meta-Ethics. In such case, we should abandon it or develop HGM instead, for example focusing on explaining and justifying Error Theory further.

Most theories of normative ethics - like most in philosophy - rest on some kind of intuition. There are different types of such basic beliefs. For example, early Aristotelian philosophers started from metaphysical presuppositions about the teleology of the World; Kantians grounded their ethics on intuitions about reason; consequentialists built theirs on the concept of "rational choice"10; many analytic philosophers started from linguistic

\footnotetext{
7 Rawls (1971).

${ }^{8}$ Hare (1963).

${ }^{9}$ Hare (1981).

${ }^{10}$ The assumption that there is an algorithm based on some rational choice theory which can help us to solve moral questions is a common assumptions of all consequentialists. For example, for classic utilitarianism such presupposition, applied to happiness of all involved parties, is a reason for utilitarian calculus as a method of answering normative questions.
} 
platitudes and "the language of morals"; while others - known as moral intuitionists worked directly from moral rules and judgements that are identified by apt emotional responses or some kind of rational procedures. The history of ethics shows us different accounts that are based on different types of intuitions. In the following remarks I will adopt quite a similar methodology. I believe that the starting point for any ethical theory should be based on some kind of strongly held judgements that need to shape a coherent state, called wide reflective equilibrium. ${ }^{11}$ However, my starting point will differ from the typical one. I want to focus on some special kinds of intuitions - beliefs about the proper functions of morality and ethics which have been strongly held over the course of the history of ethics and which presuppose contemporary normative debates. We should see them not as contingent sociological facts but as important kinds of reasons that are surprisingly persistent in the course of normative debates throughout the centuries. They exemplify some wide meta-normative beliefs that explicitly or implicitly shape history and contemporary ethics. There are many such functions. In order to find them we need to ask the question "What should morality and ethics be for?" I propose this as the main motive for further discussion and the foundation of what I call the Functional Model of Analysis:

Functional Model of Analysis (FMA): the middle ground meta-ethical framework in which the fundamental question is about the practical functions of normative domains such as morality and ethics.

There are many important normative functions of morality and ethics. I will call them functions of ethics for short, because they can be treated as goals that ethics should pursue. Philosophers can discover them through the history of ideas and history of moral philosophy. Because they are probably rooted in deep human needs, they could be also discovered with the help of psychology or sociology..$^{12}$ Regardless of the source of knowledge about them, they should be identified, compared to each other and analysed in order to find logical connections and incompatibilities. Such research, as a specific meta-ethical framework, is an important aspect of FMA. However, if FMA is not to collapse into some kind of descriptive science about morality, it needs to treat some relevant functions of ethics as important reasons to motivate and justify building normative ethics. We don't need only a descriptive knowledge about what people require from morality and ethics, but we need to assume that such requirements have some normative power in order to be the building blocks of any normative theory. This is one of the reason to focus on the history of ethics and on important reasons for its diversities - reasons, not unreasonable motives for caring about moral life. If we believe that the outcome of FMA should be any normative ethics, and as philosophers, we want to start from the history of ethics, we should assume the cognitivist account of ethics as a rational endeavour that at least manifests important normative reasons, arguments and facts.

Below I present some practical functions of ethics that are based on analysis of its history. Full presentation of them would need thorough research that is beyond the

11 Daniels (1979).

12 The psychological and evolutionary taxonomy of different functions of morality can be found in the work of Jonathan Haidt, e.g. (2007); (2013). 
scope of this paper. In the following remarks I present these practical functions only as examples of results that we can obtain through the FMA approach. The list is surely not exhaustive and could be designed in a slightly different way. However, it can be a starting point for demonstrating the FMA program.

The first type of functions of ethics have an agent-centred nature. They were especially popular in Ancient and Medieval Moral Philosophy and have been developed in contemporary thinking by virtue ethics and theistic moral philosophers. We can call them individual normative functions:

Ethics as a means to individual eudaimonia: the function of ethics is to develop tools (systems of rules, institutions, virtues, shared beliefs) that allow us to maintain and increase inner personal integrity, harmony and happiness - to live a happier or more flourishing personal life.

In the course of history we can find different ways of defining happiness and eudaimonia. Usually it was comprehended as the possession of certain goods such as virtues, friends, social esteem, autonomy or an excess amount of pleasure over pain. Since the beginning of modern times the above role of ethics has often been neglected (vide Kant). In recent years we can notice a rebirth of interest in happiness in the new branch of empirical science that is called positive psychology.

Another kind of agent-centred role of ethics is perfectionism. It assumes the following belief:

Ethics as a means to perfection: the function of ethics is to develop tools that allow us to achieve personal and human perfection, e.g. a full realization of human dignity, humanity or other personal ideals.

A perfectionist believes that the purpose of individual life is to seek personal excellence and the role of ethics is to develop tools that can help achieve this. The moral life is a life that leads to perfection in accordance with some personal ideal. Over the course of history it has been understood in very different ways. The goal would be to become a sage (the Stoics), a child of God or disciple of Jesus (Christianity), Buddha (Buddhism), Muhammad (Islam) or a superhuman being (Friedrich Nietzsche); to achieve autonomy, dignity (Kantianism) or the state of being "fully human" (humanism); or to become an "authentic person" (existentialism).

The third individual function aims at making life more meaningful. It is usually assumed by the proponents of virtue ethics, existentialism or religious thinkers. ${ }^{13}$

Practical philosophy as a means to a meaningful life: the function of ethics is to develop tools that allow the individual person to sense, discover or comprehend the meaning of their life.

${ }^{13}$ See Wolf (2010); Metz (2013); Seachris (ed.) (2013). 
The fourth function is individual salvation, sometimes understood as healing or deliverance. It is often proposed by religious and moral theology but can also be found in secular thinkers such as Leo Tolstoy and Ludwig Wittgenstein. ${ }^{14}$

Ethics as a means to salvation: the function of ethics is to develop tools that allow us to achieve the moral standard necessary for salvation, i.e. to maintain moral purity, sinlessness, impeccable attitudes, thoughts, intentions, beliefs and actions.

The second type of functions of ethics are based on agent-neutral or interpersonal considerations. They are widely recognized in the modern era due to such philosophers as Thomas Hobbes, Immanuel Kant or John Stuart Mill. We can call them the social functions of ethics.

The first of these social functions is adopted by Hobbes and many modern contractarians: ${ }^{15}$

Ethics as a means to minimize conflicts: the function of ethics is to develop tools that help to reduce conflicts of individuals' interests and to coordinate social behaviour.

Next is a fundamental belief that guides every kind of utilitarian ethics:

Ethics as a means to make the World a better place: the function of ethics is to develop tools that help to increase the quantity of well-being in the World.

The last is connected to Kantian ethics and its contractualist revision: ${ }^{16}$

Ethics as a means to reasonable agreement: the function of practical philosophy is to develop tools that every rational person would agree to or which nobody could reasonably reject.

The third type are based on what Darwall termed the second-personal standpoint. ${ }^{17}$ In this perspective, moral action should be rooted in the fact of the existence of the second person who stands before us. This fact can be seen as a source of second-person reasons or proper emotional responses driven by altruism. The last interpretation can be formulated as follows:

Ethics as a means to express and cultivate altruism: the function of ethics is to develop tools that help us to be altruistic toward those who stand before us.

\footnotetext{
${ }^{14}$ Hosseini (2013).

${ }^{15}$ Gauthier (1986); Kavka (1986); Hampton (1986); Narveson (1988).

${ }^{16}$ Rawls (1971); Scanlon (1998).

${ }^{17}$ Darwall (2006).
} 
This view is related to the belief that the main element of moral life consists of acting for the good of those who are our neighbours and who need assistance and help. A moral person is somebody who primarily cares for the real people around them, such as children, the disabled, the poor or others who need support. This approach is usually adopted by some feminist ethics and ethics of care. ${ }^{18}$ It can be also interpreted in terms of love of our neighbours in a narrower or wider sense. In this interpretation, it is essential to many religions such as Buddhism, Christianity, Hinduism, Islam and Judaism. ${ }^{19}$

The above beliefs about the functions of ethics seem to be superior to the direct moral judgements that are the basis of many intuitionist ethics. They can be seen as reasons that have survived criticism in the course of history and have remained firm throughout the centuries. I cannot justify it further here, but it can be argued that they are not just simple, basic expressions of moral emotions that are easily vulnerable to evolutionary debunking arguments, ${ }^{20}$ but strong, enduring and reason-based judgements about what morality should be all about. They are verified by moral and philosophical "experts" in the history of normative philosophy and for that reason have a higher epistemic status than the direct moral beliefs of people from our own age and culture about equality, justice, moral desert, punishment or discrimination. As I will try to argue later, they can be seen as fundamental presuppositions that lie behind many direct moral judgements, rules and historical normative theories. They also seem to have content that is broad enough to play a fundamental role in grounding some normative theory.

\section{Advantages of FMA}

The Functional Model of Analysis would not be as interesting as MGM if it were not followed by some useful implications for normative ethics. Below I outline some of the positive consequences that are related to FMA as a meta-ethical project.

\subsection{The deep content of ethical disagreement}

The history of Western moral philosophy begins with the notion of personal eudaimonia and the ideal of the perfection of human nature. Other important justifications were developed in the modern era by T. Hobbes, I. Kant and the classical utilitarians J. Bentham and J.S. Mill. All these traditions are still alive in contemporary normative philosophy. ${ }^{21}$ This diversity creates some important doubts. Everybody who studies moral philosophy at some point raises the question: Why, after so many centuries, are there still different paradigms of ethics? Why is there such diversity of normative standpoints? This fact reflects what is called "fundamental normative disagreement". It is a disagreement that is based neither on conceptual confusion nor on further non-normative facts. ${ }^{22}$ It stays

\footnotetext{
${ }_{18}^{18}$ Noddings (1984).

${ }^{19}$ Greenberg (ed.) (2008): 2 379-84.

${ }^{20}$ Singer (1982); Ruse (1998); Street (2006); Joyce (2007).

${ }^{21}$ MacIntyre (1981); Hurka (1996); Kagan (1989); Hooker (2000); Gauthier (1986); Korsgaard (1996);

Kamm (2007); Rawls (1971); Scanlon (1998).

${ }^{22}$ Ridge (2014): 64.
} 
firm even if we agree on relevant natural facts and use the same concepts with the same meaning. It is an important phenomenon of common moral life, the professional work of moral philosophers and the history of ethics. It is a base for well-known arguments for expressivism, ${ }^{23}$ or moral error-theories such as fictionalism, ${ }^{24}$ eliminativism ${ }^{25}$ or nihilism. ${ }^{26}$

One of the main normative ethical questions is "Can we solve moral disagreements and how can we achieve this in a rational way?". Unfortunately, modern meta-ethics that is focused usually on High Ground Meta-Ethics does not have fruitful resources with which to solve that puzzle in a way that can help in doing normative ethics. For example, on the level of philosophy of language, this problem is sometimes interpreted as a clash of incompatible attitudes, plans or prescriptions about some descriptive content. ${ }^{27}$ However, such an expressivist answer, even if we agree with it from an HGM point of view, does not say anything about the content - the roots of such persistent disagreement. HGM discussions about disagreement are mainly about its understanding, formal prerequisites and implications for the philosophy of moral language. ${ }^{28}$ It is also difficult to find any explication of this phenomenon in the course of normative ethics. Most books and papers in that field try to justify and defend some chosen normative position without reflecting more deeply on the problem of disagreement between them. The usual pattern of explanation assumes that the most important normative ethical distinctions are about consequentialism and non-consequentialism; the priority of right over good; virtues, rules or consequences-based ethics; different understandings of well-being; agent-centred or patient-centred vs agent-neutral ethics. If we take a look at the standard typologies that occupy handbooks of ethics, we could think that the deep problems of disagreement result from such divisions. I believe that the above distinctions are only secondary.

The main source of normative disagreement between moral philosophers lies in the implicit assumption about the right functions of morality and ethics that are presupposed by the different actors in such debates. It flows from the quite common belief that there is only one true fundamental function of morality. Most ethical theories are mono-functional. This means that their supporters consciously or unconsciously: recognize

\footnotetext{
${ }^{23}$ Ridge (2014): chap. 6.

${ }^{24}$ Mackie (1977); Joyce (2001).

${ }^{25}$ Hinckfuss (1987); Garner (2007).

${ }^{26}$ Leiter (2009); Leiter (2010).

27 See especially Chapter 6 'Disagreement' in Ridge (2014).

${ }^{28}$ Even if, e.g. there is influential meta-ethical discussion about deep moral disagreement, it is not about the typical or underlying content of moral clashes that can be found in common life, philosophical textbooks or during the course of the history of ethics, but about formal prerequisites that have to be met in order to understand and explain the very fact of the disagreement. HGM debate about disagreement shapes a discussion between descriptivist and expressivist ways of understanding moral language. As the argument goes, we cannot understand moral disagreement if the meaning of moral sentences are wholly determined by some descriptive content, e.g. the truth conditions of the moral sentence. Therefore we should accept expressivism (non-descriptivism), which says that meaning is not only determined by these elements, but also by some other non-representational states of mind or language acts, e.g. prescriptions, expressions of emotion, attitudes, plans. However, the discussion only touches the formal surface of the problem. It takes place only on the level of abstract philosophy of language, which has no obvious connection with the issues of normative and practical ethics.
} 
or accept only one genuine practical function; treat it as overriding other practical functions; or try to reduce them all to the one that is chosen. Disciples of Aristotle, Hobbes, Kant and Bentham usually reduced the domain of ethics by focusing mainly on a single question, such as "How can we live a life of eudaimon?" (Aristotle), "What system of rules is in a society's best interest?" (Hobbes), "What would be the content of synthetic a priori public rules?" (Kant), or "How can we make the World a better place?" (Bentham). Kantians usually believe that morality should be all about reasonable agreement, utilitarians that it should be all about bringing more happiness, and contemporary virtue moral philosophers that it should be all about making the individual person happier or perfecting their human nature. All other ethical considerations are subordinated to such main purposes.

Disagreements can, and surely will, arise even among those who agree that ethics can server multiple function. Such disagreements could arise from differing views about which function is paramount, or from the assignment of different weights or rankings to the various functions. However, in multiple ethical debates between rival normative theories the main reason for disagreement is an implicit assumption that there is only one proper function of morality and others are unimportant or irrelevant, or can be reduced to the chosen one. If this is true, or just true in regards to some important ethical debates, then it seems that a solution for solving the disagreement puzzle could be a hybrid theory capable of accommodating different aims and hopes of ethics. I will outline such an account later. However, first we should start from meta-normative questions: What should ethics be all about and how can we achieve it rationally? Which functions are inter-dependent or contradictory and to what extent? Which functions should be most important? Can we fit them into a plausible hierarchy? Is there any independent meta-normative account that can help us to solve that problem? All in all, we need to set these questions in front of us and try to answer them directly. However, this requires us to redirect the main meta-ethical pursuit from HGM to MGM and the Functional Model of Analysis.

\subsection{The structure of moral theories}

The most popular topologies that can be found in handbooks of normative ethics rely on the typical structure of ethical theories. There are virtue ethics, deontology and consequentialism. In accordance with their etymology, we can roughly say that the first is focused mainly on virtues, the second on rules and obligations and the last on consequences. As a result of this conceptualization, many debates in ethics are about the priority of one structure over others: Should we judge acts by rules, virtues or consequences? Is "right" prior to "good" or vice versa? Can we define virtues in terms of good acts or obligatory rules? These are typical questions that concern normative ethics. However, one of the interesting implications of FMA is the claim that such problems are only secondary and depend hugely on an answer to the question "What should ethics be all about?" The structure of ethical theory is not as important as the practical function of ethics that it assumes - it is usually a consequence of assumed function of ethics. Therefore, philosophical discussions that are focused directly on the structure of ethics 
itself without functional analysis usually are not perceived as conclusive by those who accepts different primary normative functions.

Any normative theory is built with the help of some "focal points", a term introduced by S. Kagan. ${ }^{29}$ Focal points are important types of properties of facts which constitute the central features for making normative judgements. Examples of focal points are consequences, rules, motives, norms, character traits, decision-making procedures and institutions. A theory of moral philosophy can use any combination of these directly or indirectly. Theoretically, we can judge acts by rules which are justified by institutions; virtues by acts which are justified by consequences; rules by acts which are justified by virtues, etc. If we provide only four focal points we can imagine sixteen possible combinations of them, shaping sixteen structures of ethics. The simplest and most well-known structures are direct consequentialism, deontology and virtue ethics. For example, act-consequentialism makes consequences the primary focal point, evaluating an act directly in terms of good consequences: other focal points, such as rules, are assessed only indirectly via expected acts that they can bring. In contrast, rule-consequentialism and deontology make rules the primary focal point and evaluate others indirectly in terms of the rules. Virtue ethics makes traits of character the primary focal point. Acts or rules are valued indirectly via virtues which they express or presuppose. We can imagine much more complicated structures of focal points which can describe some moral theories. However, the reasons for choosing any one of them do not lie in the focal points themselves. I believe that they flow from answers to the question "What should morality and ethics be for?"

It is highly rational to correlate particular focal points with particular practical normative functions. For example, if we believe that ethics should be treated mainly as a means to a better World, then the most important focal point seems to be our acts, assessed by their direct consequences. If ethics is all about bringing perfection to our life, then the most important focal point should be our character. If ethics is all about salvation, which can be achieved by those who have pure souls, then the main focal points should be intentions and motives. On the other hand, if ethics is a means of reducing conflicts and maximizing agreement, then the most important focal point should be institutions and rules, because only universal and public rules can optimize social coordination and serve as a universal means of justifying our actions to each other. Therefore, choosing a rational structure for moral theory depends on answering the main question that shapes FMA.

\subsection{A unifying account of normative standpoints}

In the teleological approach, the value of some actions, rules or virtues depends solely on the values and goods that they lead to. These goods are comprehended in very different ways. There are welfarists who endorse hedonism, desire-based or preference theories in which values must always be valuable to somebody. Derek Parfit also distinguished list-theories that present a list of many plural goods such as knowledge, pleasure, beauty,

${ }^{29}$ Kagan (2000). 
love, friendship, autonomy, etc. ${ }^{30}$ However, there is also one other possibility which is connected to FMA.

If most traditional theories of ethics have different aims, understood as answers to the question about the proper function of morality and ethics, such functions can be treated as separate values that can be rationally pursued, prioritized and optimized within a consequentialist framework. There is a value of agent-centred happiness that corresponds to the eudaimonistic function, a value of agent-centred perfection that corresponds to the perfectionist function, a utilitarian agent-neutral value that corresponds to the "making the World a better place" function, a value of minimizing social conflict or bringing rational agreement that is connected with Hobbesian or Kantian functions of morality. This interpretation gives interesting results: such values can be the foundation for a unifying account of the most important approaches in normative ethics, brought together within one teleological framework.

In contemporary ethics there are a few attempts that try to consequentialize theories that are traditionally viewed as non-consequentialist. There is rule-consequentialism ${ }^{31}$ or virtue-consequentialism, ${ }^{32}$ which mimic the typical structure of rule-based deontology or motive-based virtue ethics in a consequentialist framework. We can also find a type of Kantian consequentialism, which assumes that the main purpose of ethical inquiry is to find rules that every rational person could or would accept. This way of thinking can be discovered in the work of Richard M. Hare, ${ }^{33}$ David Cummiskey ${ }^{34}$ or Derek Parfit. ${ }^{35}$ Another form of such an approach can be found in Michael Ridge's paper "Consequentialist Kantianism," ${ }^{36}$ in which he presents a possible theory that is agent-neutral and teleological in nature, but preserves Kantian intuitions about the validity of deontic side-constraints. There is also a more formal technique for exploiting what is called the "consequentialist vacuum cleaner" 37 or "consequentialist umbrella" 38 in the works of Douglas Portmore. ${ }^{39}$ He tries to explain and justify what he calls the Deontic Equivalence Thesis: "For any remotely plausible non-consequentialist theory, $\mathrm{M}$, there is a consequentialist counterpart theory, $\mathrm{M}^{*}$, that yields, in every possible world, the exact same set of deontic verdicts that $M$ does, including not only such verdicts as 'permissible' and 'impermissible,' but also such verdicts as 'supererogatory.'" 40

The Functional Model of Analysis can allow us to consequentialize moral theories in one other way. It can utilize the possibility of treating different functions of morality as separate values that can be optimized within a consequentialist framework. To explain this, let me first describe mono-functional consequentialism. For example, if we assume

\footnotetext{
30 Parfit (1984): 493.

31 Hooker (2000).

32 Driver (2001); Driver (2009); Bradley (2005).

33 Hare (1997).

34 Cummiskey (1990); Cummiskey (1996).

35 Parfit (2011).

36 Ridge (2009).

37 McNaughton, and Rawling (1991): 168.

38 Lousie (2004).

39 Portmore (2011).

40 Portmore (2007): 54.
} 
that the only function of ethics is to develop tools that allow us to achieve personal and human perfection, the resulting theory can be called perfectionist virtue consequentialism. It can claim that we should be guided by virtues, beliefs, intentions and supporting institutions that optimize our personal development. If we assume that the only function of ethics is to reduce conflicts of individuals and coordinate social behaviour, then we get contractarian institution consequentialism, whereby we should act according to the rules which constitute social institutions that would minimize conflicts and maximize social coordination. Contractualist rule consequentialists could believe that we should act according to the rules that would optimize realization of the Kantian idea of reasonable agreement between equal and autonomous subjects; and consequentialists of salvation, that we should act in a way that would optimize realization of the standards necessary for salvation. The above standpoints are only examples of how we can consequentialize different traditions of ethics using the Functional Model of Analysis.

However, mono-functional theories imply practical judgements that are at odds with our deep moral intuitions and cannot fulfil all the needs and hopes that are placed in ethics. The history of ethics justifies a sceptical claim that we will not be able to reduce all important normative aims into one mono-functional theory. It can be predicted that all single-role theories will always be criticized by those who accept other answers to the question "What should morality and ethics be for?" Therefore, one solution to that disagreement problem is to accept that the best normative theory of ethics should be rich in its functions - should be a version of a hybrid functions approach. It can give us the hope of unifying different moral philosophies without diminishing some of their important aspects. Most of us would love to have one philosophical account which covers how to live a happy and fruitful life; which virtues make us better humans; how to act to increase the good; which rules should be followed to optimize social cooperation; which choices in our lives could we justify to each other. Religious believers also seek in practical philosophy help in achieving salvation, a means to properly respond to God's will or God's unconditional love. Many of these aims are rationally connected with each other and others are contradictory. The Functional Model of Analysis can be a tool for researching these possibilities, in the hope of finding an optimal set of aims that can be realized in plurality.

FMA can be a basis for building such a hybrid theory within a consequentialist framework. If it is true that the ideal normative theory should fulfil as many expectations as possible concerning the roles of normative domains, then, if we accept FMA and consequentialism, we can develop the theory that can be called Hybrid Function Consequentialism:

Hybrid Function Consequentialism (HFC): we should act according to some important focal points $P_{1} \ldots P_{n}$ with contents $C_{1} \ldots C_{n}$ that are selected on the basis of considerations about which kind of $P$ with $C$ will bring the best realization of the best mix of normative functions $F_{1 \ldots} F_{n}$.

Any particular version of HFC needs to rest on many considerations. Some are related to global issues of rational choice in the face of plural values and multi-criterial optimization. However, such issues are not unique to ethics but are important to any theory 
that deals with questions of rational choice. For example, we can predict that we will not be able to combine all the functions in one theory without losing some of the content of each function. We can achieve equilibrium of different functions only by some kind of compromise. However, if we work within a broad consequentialist framework, theoretically we can achieve some optimal realization of all or most of these functions in one theory. We just need a sound analysis of such practical functions, interpretation of their realization in practice, corresponding focal points, and tools of decision theory for optimizing the realization of multiple aims. The above formal definition also exemplifies a feature of FMA that I discussed earlier: the structure of the theory, reflected in the proper arrangement of focal points $P_{1} \ldots P_{n^{\prime}}$ is entirely dependent on choosing normative functions $F_{1 . .} F_{n}$. Therefore, we cannot decide in advance whether it should be virtue ethics, rule-based ethics or direct consequentialist ethics without deciding on the roles that morality should play.

\section{Potential Problems}

\subsection{Theoretical and practical functions}

Meta-ethical realists can claim that the main function of ethics is not to achieve some practical goals for individuals or societies but rather to discover truth and describe it in an appropriate theoretical system. Its practical functions are irrelevant or dependent on the epistemic or truth-seeking role of normative philosophy. According to this view the main function of ethics is to develop tools that allow us to discover moral truth and describe it in a methodologically appropriate manner. We can also reinterpret above assumption in a way that it will have more normative taste. Someone might claim that the main function of ethics is to serve people's desires or aims to do the right thing or to bring about states with moral value. Thus ethics is not only about finding the truth, but rather finding and guiding how to achieve it.

However, there is no good direct way to discover "moral truth" or "right thing to do" in ethics. Such lofty aims like "discovering truth" give us too simplistic a picture. Unfortunately, the history of ethics teaches us, that anybody who tries to find moral truth that could be publically defended, anybody who doesn't want to be accused of unjustified, unreasonable fundamentalism, has to depend on some indirect method usually based on moral or non-moral intuitions. For example, G.E. Moore and many of his meta-ethical disciples believed that we need to determine the meaning of moral words; R.M. Hare grounded ethics in the logic of moral discourse; moral intuitionists like J. Rawls believed that our strong and widely shared moral convictions should be tested by some kind of reflective equilibrium; Kantians tried to discover some necessary practical reasons that in fact are intuitions about rationality. FMA can also be seen as an indirect way of discovering normative truth. According to such a realist interpretation, we just need to accept that all the functions mentioned above express basic meta-normative intuitions that resemble some existing facts about morality and ethics that are spread across historical theories. The proper way of grasping these facts is by researching the practical functions of ethics. These facts, taken into account by some future proper ethical theory, will fix the reference for moral terms, rules and judgements. 
However, we do not need to assume that the Functional Model of Analysis provides the best way of finding a moral truth that is "out there". We can also accept moral anti-realism or expressivism and focus on the practical function of ethics for solely pragmatic reasons. We only need to believe that ethics has something important to offer beyond useless fiction and myths. We can take a constructivist approach in an expressivist fashion. If we comprehend ethics as a rational endeavour that is important in personal and social practice, we should construct a theory that tries to fulfil the most significant practical functions of ethics.

To sum up, FMA and the approach proposed here can be seen as an indirect way of discovering moral truth, or as the tool for theoretical construction in accordance with some anti-realist meta-ethical stance. Therefore, it takes an independent stance on the debate about moral realism and anti-realism.

\subsection{FMA vs the Roles of Agency Model}

It could be claimed that the Functional Model of Analysis is inferior to other similar models of MDM. One of them is - as I will call it - the Roles of Agency Model (RAM). By RAM I mean an analytical framework which assumes that the proper way to explore moral theories, or at least the deontology-consequentialism debate, is to focus on different roles of moral agency. This is implicit in T. Chappell's paper ${ }^{41}$ about the paradox of deontology, in which he defends deontic constraints.

Chappell argues that the so-called paradox of deontology is in fact a reductio ad absurdum of the conjunction of two premises: "It's good to keep deontological constraints" and "The role of agency is to bring about goodness". He believes that the second premise is false and tries to vindicate deontology by recalling different roles of agency which bring different kinds of rationality. The role of bringing about goodness he connects with the rationality of maximization (teleological rationality), but other non-consequentialist roles, such as expressing loyalty to a value, with other kinds of rationality. ${ }^{42}$ In his opinion this justifies the belief in the validity of deontic side-constraints.

Showing that different ethical theories postulate different roles of agency makes an important point. Perfectionist virtue ethics, contractarianism, utilitarianism or Kantianism can presuppose different roles of agency. However, I believe that a better interpretation of such diversities is one that focuses on the functions of ethics and moral life rather than on roles of agency.

There are two main problems with Chappell's approach. First of all, it begs the question of which functions of ethics should be pursued. If the fundamental problem of MGM is about roles of moral agency, then all ethical standpoints must be reduced to the perspective of the moral agent. Even if the agent-centred standpoint is really important in ethics, it is not the only one that matters. There are many reasons not to reduce ethics only to the life of the moral agent, and they are satisfactorily developed in patient-centred, social-based or agent-neutral theories that are well represented in the history of ethics.

\footnotetext{
${ }^{41}$ Chappell (2011).

${ }^{42}$ Chappell (2011): 274-5.
} 
All these reasons, if we connect them with the fact about persistent ethical disagreement, support departure from mono-functional ethics towards a hybrid way of thinking about the functions of morality. As I have noted before, all single-function theories, or ones that are just not broad enough, will always be criticized by those who accept other answers to the question "What should morality and ethics be for?"

The second problem of RAM is that it presupposes a queer notion of rationality that is not known outside the narrow field of normative ethics. Chappell's non-teleological rationality is based on an ad hoc interpretation of moral agency and cannot be well grounded without direct references to common moral intuitions. However, the phenomenology of morality, even if it supports deontic constraints, reveals nothing about the different kinds of rationality that are supposed to ground them. Reasons for holding or abandoning deontic side-constraints are hidden from direct philosophical insight. Moreover, various roles of agency cannot explain or justify different kinds of rationality, because roles of agency and types of rationality are two independent things. We can always ask an important open question that undermines Chappell's approach: if moral agency has several roles to play, why do we not claim that rational ethics should optimize these roles in a consequentialist framework? As Douglas Portmore states, "Why, then, would the moral sphere be the only sphere of rational conduct in which the maximizing conception of rationality didn't hold?" ${ }^{43}$ Such a conception is a compelling idea of consequentialism and can be articulated in the following way:

The Teleological Conception of Reasons (TCR): The reasons there are for and against performing a given act are wholly determined by the reasons there are for and against preferring its outcome to those of its available alternatives, such that, if $S$ has most reason to perform $a i$, then, of all the outcomes that $S$ could bring about, $S$ has most reason to desire that oi (i.e., ai's outcome) obtains. ${ }^{4}$

\subsection{Consequentialism and deontic constraints}

In the chapter 3.3 I proposed a sketch of normative ethical theory that can be ground on Functional Model of Analysis. I've called it Hybrid Function Consequentialism. I've proposed it solely as an exemplification of how FMA can be used in order to build some normative ethics. Further explanation, justification and defence of HFC is beyond the scope of this paper. However, based on provided example, it can be argued, though, that the cure for disagreement in normative ethics proposed here relies on a problematic assumption about the validity of consequentialism. It has many rivals and there is wide debate about deontic side-constraints. Some philosophers defend them by abandoning consequentialism; ${ }^{45}$ others criticize these attempts. ${ }^{46}$

\footnotetext{
43 Portmore (2007): 49.

44 Portmore (2009): 333.

45 Kamm (1993); Hurley (1997); Otsuka (2006); Hsieh, Strudler, and Wasserman (2006); Chappell (2011).

${ }^{46}$ Parfit (1984): chap. 4.; Scheffler (1985); Scheffler (1988); Kagan (1989): chap. 5,9.; Portmore (1998);

Bennett (1998): chap. 10.; Cummiskey (1990); Cummiskey (1996); Brand-Ballard (2004).
} 
The Functional Model of Analysis need not be connected with moral consequentialism and does not presuppose any conception of rationality. The theory of rationality needs to be established by independent research. However, I can find no reasons why as Portmore put it ${ }^{47}$ - the moral sphere is special and presupposes a different, elsewhere unknown concept of rationality. Of course, there are different aims, functions, rules and features that describe other fields of rational practice, but we should not confuse these with different types of rationality. It is a reasonable assumption that there is no specific rationality of ethics, but rather the same kind of practical rationality across every practical domain that is described in decision and game theory. If this is true, consequentialism is the first choice for normative ethics. What would be its practical outcome depends on many details like chosen values that should be optimised.

We should also not confuse accepting a teleological theory of rationality with the need to criticize moral deontic constraints. There is no need to abandon consequentialism and the teleological theory of rationality if we accept that we should always follow some moral rules. There are good reasons to believe that most or even all interesting normative standpoints can be interpreted as forms of consequentialism. As I noted earlier, to describe this viewpoint D. NcNaughton and P. Rawling use "the consequentialist vacuum cleaner" metaphor, ${ }^{48} \mathrm{~J}$. Luisie the "consequentialist umbrella" 49 and D. Portmore the "consequentializing deontology" procedure..$^{50}$

Moreover, we can explain the importance of deontic constraints by the exercise of the Functional Model of Analysis. Moral constraints seem to be valid not because they conserve some other type of rationality, but because they exercise important functions of ethics. Deontic constraints can be seen as a way of emphasizing individual-based or second-personal functions. In the first interpretation, agent-centred deontic normative reasons are the result of a belief that ethics has to support the moral agent somehow, that it exists for the individual person who is a moral agent. If we assume that happiness, perfection or salvation of the individual agent is more important than any social goal, and that because of this the most important values have an agent-centred nature, then it is rational in the teleological sense to promote agent-centred values, even if they bring worse consequences when assessed from a social or neutral point of view. In this interpretation I should not break deontic constraints because they are the rational way of minimizing serious harm to myself. The second way of understanding deontic side-constraints assumes that they flow from the overriding nature of second-personal, altruistic functions of ethics. If the agent-relative value of caring for neighbours who stand before us is more vital than the value of making the World a better place from a neutral point of view, then it is rational to protect or help our neighbours even if the overall consequences from a neutral point of view would be worse.

\footnotetext{
47 Portmore (2007): 49.

${ }^{48}$ McNaughton, and Rawling (1991); (1998): 41.

${ }^{49}$ Lousie (2004).

${ }^{50}$ Portmore (2007); (2009); (2011).
} 


\section{Conclusions}

In this paper I have presented the Functional Model of Analysis, which is a version of what I called middle ground meta-ethics. It is a meta-ethical framework that can be useful for doing normative ethics. It presupposes that the main meta-ethical question is "What kind of practical roles should ethics play and how can we achieve them rationally?" FMA can also be used as a fruitful model of explanation. We can recognize that the mono-functional approach that is popular in ethics is a source of fundamental, persistent disagreement. The solution to this is to research different functions of morality and to build a theory that could combine many of them in one hybrid approach. FMA can also help to explain the reasons for choosing different structures of ethics - the architectures of important focal points. Debates about proper structures of ethics can be inconclusive if they are conducted without additional primary analysis of the functions of ethics. In this respect, FMA can help to explain the importance of deontic constraints, direct consequences, or virtuous character traits in a proper theory of ethics. FMA also offers the hope of finding a unifying normative theory that could combine many historical traditions. In the paper I gave a very brief sketch of it in the form of Hybrid Functional Consequentialism.

Acknowledgments. This work was supported by the National Science Centre Poland under Grant DEC-2012/05/B/HS1/02781. The paper is an extended and developed further version of the chapter 5.1 from the book Etyka normatywna. Między konsekwencjalizmem a deontologia. ${ }^{51}$

\section{References}

Bennett J. F. (1998), The Act Itself, Clarendon Press, Oxford.

Blackburn S. (1998), Ruling Passions: A Theory of Practical Reasoning, Oxford University Press, Oxford.

Bradley, B. (2005), “Virtue Consequentialism,” Utilitas 17 (3): 282-298.

Brand-Ballard J. (2004), "Contractualism and Deontic Restrictions," Ethics 114 (2): 269-300.

Chappell T. (2011), “Intuition, System, and the 'Paradox' of Deontology," [in:] Perfecting Virtue, ed by. Lawrence Jost, Julian Wuerth, Lawrence Jost, and Julian Wuerth, Cambridge University Press, Cambridge: 271-288.

Cummiskey D. (1990), “Kantian Consequentialism,” Ethics 100 (3): 586-615.

Cummiskey D. (1996), Kantian Consequentialism, Oxford University Press, New York.

Daniels N. (1979), “Wide Reflective Equilibrium and Theory Acceptance in Ethics," The Journal of Philosophy 76 (5): 256-282.

Darwall S. (2006), The Second-Person Standpoint: Morality, Respect, and Accountability, Harvard University Press, Cambridge.

Driver J. (2001), Uneasy Virtue, Cambridge University Press, Cambridge.

Driver J. (2009), Consequentialism, Taylor and Francis, London.

Fisher A. (2014), Metaethics, Routledge, London.

Garner R. (2007), “Abolishing Morality," Ethical Theory and Moral Practice 10 (5): 499-513.

${ }^{51}$ Saja (2015). 
Gauthier D. P. (1986), Morals by Agreement, Clarendon Press, Oxford.

Gibbard A. (1990), Wise Choices, Apt Feelings: A Theory of Normative Judgment, Harvard University Press, Cambridge.

Gibbard A. (2012), Meaning and Normativity, Oxford University Press, Oxford.

Greenberg Y.K. (ed.) (2008), Encyclopedia of Love in World Religions, Vol. 2, ABC-CLIO, Santa Barbara, Denver, Oxford.

Haidt J. (2007), “The New Synthesis in Moral Psychology," Science 316 (5827): 998-1002.

Haidt J. (2013), The Righteous Mind: Why Good People are Divided by Politics and Religion, Penguin, London.

Hampton J. (1986), Hobbes and the Social Contract Tradition, Cambridge University Press, Cambridge.

Hare R. M. (1963), Freedom and Reason, Oxford University Press, Oxford.

Hare R. M. (1981), Moral Thinking: Its Levels, Methods and Point, Clarendon Press, Oxford.

Hare R. M. (1997), “Could Kant Have Been An Utilitarian?,” [in:] Sorting Out Ethics, Clarendon Press; Oxford University Press, Oxford; New York: 147-65.

Hazlett A. (2013), A Luxury of the Understanding: On the Value of True Belief, Oxford University Press, Oxford.

Hinckfuss I. (1987), The Moral Society: Its Structure and Effects, Australian National Univ., Canberra.

Hooker B. (2000), Ideal Code, Real World: A Rule-Consequentialist Theory of Morality, Clarendon Press, Oxford.

Hosseini S. R. (2013), “Meaning in Life: A Wittgensteinian Approach," University of Johannesburg, URL = https://ujdigispace.uj.ac.za/handle/10210/8676 [Accessed 15.06.2013].

Hsieh N.; Strudler A.; Wasserman D. (2006), "The Numbers Problem," Philosophy \& Public Affairs 34 (4): 352-372.

Hurka T. (1996), Perfectionism, Oxford University Press, New York.

Hurley P. (1997), "Agent-Centered Restrictions: Clearing the Air of Paradox," Ethics 108 (1): 120-146.

Joyce R. (2001), The Myth of Morality, Cambridge University Press, Cambridge.

Joyce R. (2007), The Evolution of Morality, The MIT Press, Cambridge.

Kagan S. (1989), The Limits of Morality, Clarendon Press, Oxford.

Kagan S. (2000), "Evaluative Focal Points," [in:] Morality, Rules, and Consequences: A Critical Reader, ed by. Brad Hooker, Elinor Mason, and Dale Miller, Edinburgh University Press, Edinburgh: 134-155.

Kamm F. (1993), Morality, Mortality. Volume II: Rights, Duties, and Status, Vol. 3, Oxford University Press, Oxford.

Kamm F. (2007), Intricate Ethics: Rights, Responsibilities, and Permissible Harm, Oxford University Press, Oxford; New York.

Karlander K. (2008), The Normativity of Thought and Meaning, Acta Universitatis Stockholmiensis, Stockholm.

Kavka G. (1986), Hobbesian Moral and Political Theory, Princeton University Press, Princeston. Korsgaard C. (1996), Creating the Kingdom of Ends, Cambridge University Press, Cambridge; New York.

Leiter B. (2009), “Moral Skepticism and Moral Disagreement in Nietzsche," URL = http:/ / chicagounbound.uchicago.edu/cgi/viewcontent.cgi?article $=1195 \&$ context $=p u-$ blic_law_and_legal_theory [Accessed 13.07.2010]. 
Leiter B. (2010), "Moral Skepticism and Moral Disagreement: Developing An Argument From Nietzsche", URL = http:// onthehuman.org/2010/03/moral-skepticism-and-moral-disagreement-developing-an-argument-from-nietzsche/ [Accessed 13.04.2010].

Lousie J. (2004), "Relativity of Value and The Consequentialist Umbrella," The Philosophical Quarterly 54 (217): 518-536.

MacIntyre A. (1981), After Virtue: A Study in Moral Theory, University of Notre Dame Press, USA. Mackie J. L. (1977), Ethics: Inventing Right and Wrong, Penguin, London.

McNaughton D.; Rawling, P. (1991), “Agent-Relativity and the Doing-Happening Distinction," Philosophical Studies 63 (2): 167-185.

McNaughton D.; Rawling, P. (1998), “On Defending Deontology,” Ratio 11 (1): 37-54.

Metz T. (2013), Meaning in Life, Oxford University Press, Oxford.

Miller A. (2003), An Introduction to Contemporary Metaethics, Polity Press, Cambridge.

Moore G. E. (1903), Principia Ethica, University Press, Cambridge.

Narveson J. (1988), The Libertarian Idea, Temple University Press, Philadelphia.

Noddings N. (1984), Caring, a Feminine Approach to Ethics \& Moral Education, University of California Press, California.

Otsuka M. (2006), “Saving Lives, Moral Theory, and the Claims of Individuals," Philosophy E Public Affairs 34 (2): 109-135.

Owens D. (2002), Reason Without Freedom: The Problem of Epistemic Normativity, Routledge, New York,

Parfit D. (1984), Reasons and Persons, Clarendon Press, Oxford.

Parfit D. (2011), On What Matters, Vol. I, Oxford University Press, Oxford.

Portmore D. (1998), “Can Consequentialism Be Reconciled with Our Common-Sense Moral Intuitions?", Philosophical Studies 91 (1): 1-19.

Portmore D. (2007), “Consequentializing Moral Theories," Pacific Philosophical Quarterly 88 (1): 39-73.

Portmore D. (2009), “Consequentializing," Philosophy Compass 4 (2): 329-347.

Portmore D. (2011), Commonsense Consequentialism: Wherein Morality Meets Rationality, Oxford University Press, New York.

Price H.; Blackburn S.; Brandom R.; Horwich P.; Williams M. (2013), Expressivism, Pragmatism and Representationalism, Cambridge University Press, Cambridge.

Rawls J. (1971), A Theory of Justice, The Belknap Press of Harvard University Press, Cambridge.

Ridge M.; Fletcher G. (eds.) (2014), Having It Both Ways: Hybrid Theories in Meta-Normative Theory, Oxford University Press, Oxford.

Ridge M. (2009), “Consequentialist Kantianism," Philosophical Perspectives 23 (1): 421-438.

Ridge M. (2015), Impassioned Belief, Oxford University Press, Oxford.

van Roojen M. (2015), Metaethics. A Contemporary Introduction, Routledge, New York.

Ruse M. (1998), Taking Darwin Seriously: A Naturalistic Approach to Philosophy, Prometheus Books, USA.

Saja K. (2015), Etyka normatywna. Między konsekwencjalizmem a deontologia, Universitas, Kraków.

Scanlon T. (1998), What We Owe to Each Other, The Belknap Press of Harvard University Press, Cambridge.

Scheffler S. (1985), “Agent-Centred Restrictions, Rationality, and the Virtues," Mind 94 (375): 409-419.

Scheffler S. (1988), "Introduction," [in:] Consequentialism and Its Critics, ed by. Samuel Scheffler, Oxford University Press, USA: 1-13. 
Seachris J.W. (ed.) (2013), Exploring the Meaning of Life: An Anthology and Guide, Wiley-Blackwell, Chichester, West Sussex; Malden, MA.

Singer P. (1982), “Ethics and Sociobiology," Philosophy \& Public Affairs: 40-64.

Street S. (2006), "A Darwinian Dilemma for Realist Theories of Value," Philosophical Studies 127 (1): 109-166.

Wolf S. (2010), Meaning in Life and Why It Matters, Princeton University Press, Princeton, Oxford. 